\title{
Differential Susceptibility to Neurotoxicity Mediated by Neurotrophins and Neuronal Nitric Oxide Synthase
}

\author{
Amer F. Samdani, ${ }^{1}$ Cheryl Newcamp, ${ }^{1}$ Annelies Resink, ${ }^{1}$ Fabrizio Facchinetti, ${ }^{1}$ \\ Brian E. Hoffman, ${ }^{1}$ Valina L. Dawson, ${ }^{1,2,3}$ and Ted M. Dawson ${ }^{1,2}$ \\ Departments of ${ }^{1}$ Neurology, ${ }^{2}$ Neuroscience, and ${ }^{3}$ Physiology, Johns Hopkins University School of Medicine, Baltimore, \\ Maryland 21287
}

\begin{abstract}
NMDA neurotoxicity, which is mediated, in part, by formation of nitric oxide (NO) via activation of neuronal NO synthase (nNOS), is modulated by neurotrophins. nNOS expression in rat and mouse primary neuronal cultures grown on a glial feeder layer is significantly less than that of neurons grown on a polyornithine (Poly-O) matrix. Neurotrophins markedly increase the number of nNOS neurons, nNOS protein, and NOS catalytic activity and enhance NMDA neurotoxicity via NO-dependent mechanisms when neurons are grown on glial feeder layers. In contrast, when rat or mouse primary cortical neurons are grown on a Poly-O matrix, neurotrophins have no influence on nNOS neuronal number or NOS catalytic activity and reduce NMDA neurotoxicity. Primary neuronal cultures from mice lacking nNOS grown on a glial feeder layer fail to respond to
\end{abstract}

Neurotrophins consist of a family of growth factors, including nerve growth factor (NGF), brain-derived neurotrophic factor (BDNF), neurotrophin-3 (NT-3), and neurotrophin-4/5 (NT-4/5), which act on high-affinity receptor tyrosine kinases, TrkA, TrkB, and TrkC, to promote neurite extension, neuronal survival, and differentiation (Barde, 1994; Barbacid, 1995; Thoenen, 1995). Other growth factors such as glial-derived neurotrophic factor (GDNF), ciliary neurotrophic factor (CNTF), insulin-like growth factor (IGF-1), and transforming growth factor- $\beta$ (TGF- $\beta$ ) also influence neuronal survival and differentiation (Lindsay, 1994; Birling and Price, 1995). Besides having a role in neuronal differentiation and survival, neurotrophins can attenuate neuronal cell death caused by excitotoxins, glucose deprivation, and ischemia (Shigeno et al., 1991; Davies and Beardsall, 1992; Frim et al., 1993; Burke et al., 1994; Cheng and Mattson, 1994; Lindholm,

\footnotetext{
Received Jan. 22, 1997; revised March 21, 1997; accepted April 3, 1997.

This work was supported in part by United States Public Health Service Grants NS 33277 and NS 01578 and the International Life Sciences Institute to T.M.D., and United States Public Health Service Grant NS 33142 and the National Alliance on Research for Schizophrenia to V.L.D. A.F.S. is a recipient of the Howard Hughes Medical Student In-Residence Research Fellowship and the Harold Lamport Research Grant. We thank Ann Schmidt for secretarial assistance, Allen Mandir for assistance with the statistical analyses, and Regeneron Pharmaceuticals, Tarreytown, NY, for a portion of the BDNF used in this study.

Under an agreement between the Johns Hopkins University and Guilford Pharmaceuticals, T.M.D. and V.L.D. are entitled to a share of sales royalty received by the University from Guilford. T.M.D. and the University also own Guilford stock, which is subject to certain restrictions under University policy. The terms of this arrangement have been reviewed and approved by the University in accordance with its conflict of interest policies.

Correspondence should be addressed to Dr. Ted M. Dawson, Department of Neurology and Neuroscience, Johns Hopkins University School of Medicine, Pathology 2-210, 600 North Wolfe Street, Baltimore, MD 21287.

Copyright (C) 1997 Society for Neuroscience 0270-6474/97/174633-09\$05.00/0
}

neurotrophin-mediated enhancement of neurotoxicity. Together, these results indicate that nNOS expression and NMDA NO-mediated neurotoxicity are dependent, in part, on the culture paradigm, and neurotrophins regulate the susceptibility to NMDA neurotoxicity via modulation of nNOS. Furthermore, these results support the idea that NMDA neurotoxicity in culture is critically dependent on the developmental state of the neurons being assessed and suggest that, when cortical neurons are cultured on a glial feeder layer, they do not reach nearly as mature a phenotype as when grown on a Poly-O matrix.

Key words: neurotrophins; growth factors; excitotoxicity; glutamate; NMDA; nitric oxide
1994; Mattson et al., 1995; Nakao et al., 1995; Anderson et al., 1996). Despite the abundance of in vitro and in vivo data that neurotrophins enhance the survival of neurons after neuronal injury, Choi and collaborators recently provided provocative data that neurotrophins under certain conditions enhance excitotoxic insults (Koh et al., 1995).

Nitric oxide (NO) is an important biological messenger with many diverse physiological actions throughout the body (Nathan, 1992; Schmidt and Walter, 1994; Yun et al., 1996). NO is synthesized from L-arginine by NO synthase (NOS), of which three isoforms have been identified, representing the products of three distinct genes that include neuronal NOS (nNOS, Type 1), immunological NOS (iNOS, Type 2), and endothelial NOS (eNOS, Type 3) (Bredt and Snyder, 1994; Marletta, 1994; Nathan and Xie, 1994). Neurotoxicity elicited by glutamate acting via NMDA receptors is mediated, in part, by excess production of NO by nNOS (Dawson and Snyder, 1994; Dawson and Dawson, 1996). NMDA neurotoxicity in primary cerebral cortical cultures is prevented by a variety of NOS inhibitors (V. Dawson et al., 1991, 1993; T. Dawson et al., 1993, 1995), and cortical cultures from nNOS-deficient $\left(\mathrm{nNOS}^{-}\right)$mice are resistant to neurotoxicity (Dawson et al., 1996). These results have been replicated independently in various other culture systems (for review, see Dawson and Snyder, 1994; Dawson and Dawson, 1996). However, some difficulties in replicating these findings may relate to inadequate expression of nNOS neurons in the cultures used (Hewett et al., 1994).

nNOS expression is increased after NGF treatment in PC-12 cells (Hirsch et al., 1993; Peunova and Enikolopov, 1995) and in 
rat spinal cord after treatment with BDNF, NT-3, and NT-4 (Huber et al., 1995) and basal forebrain cholinergic neurons (Holtzman et al., 1994, 1996). Because nNOS expression is regulated by neurotrophins, we wondered whether the potentiation of excitotoxicity by neurotrophins is mediated via increases in nNOS expression. We now show that nNOS levels and NO-dependent neurotoxicity are critically dependent on the culture paradigm. Neurons grown on a glial feeder layer express low levels of nNOS and do not exhibit NO-dependent neurotoxicity, whereas neurons grown on a polyornithine (Poly-O) matrix express high levels of nNOS and exhibit NO-dependent neurotoxicity in response to NMDA. Moreover, we show that neurotrophin enhancement of NMDA neurotoxicity occurs via increases in nNOS when neurons are grown on a glial feeder layer, whereas neurotrophins are neuroprotective when neurons are grown on a Poly-O matrix.

\section{MATERIALS AND METHODS}

Cell culture. Primary cortical cultures were prepared from gestational day 16 fetal Sprague Dawley rats and C57BL6 mice in a procedure modified from that described previously (V. Dawson et al., 1991, 1993). Briefly, the cortex from fetal mice was dissected, and the cells were dissociated by trituration in modified Eagle's medium (MEM), 20\% horse serum, $25 \mathrm{mM}$ glucose, and $2 \mathrm{mM}$ L-glutamine after a $30 \mathrm{~min}$ digestion in $0.027 \%$ trypsin/saline solution. Cortex from fetal rats was dissociated by trituration in MEM, $10 \%$ fetal bovine serum, $10 \%$ horse serum, and $2 \mathrm{~mm}$ L-glutamine after a $30 \mathrm{~min}$ digestion in $0.027 \%$ trypsin/saline solution. The cells were plated on $15 \mathrm{~mm}$ multiwell plates coated with polyornithine (Poly-O) or a glial layer. At $4 \mathrm{~d}$ after plating, the cells were treated with 5-fluoro-2-deoxyuridine for $3 \mathrm{~d}$ to inhibit proliferation of nonneuronal cells. Cultures derived from mice then were maintained in MEM, 10\% horse serum, $25 \mathrm{~mm}$ glucose, and $2 \mathrm{mM}$ L-glutamine in an $8 \%$ $\mathrm{CO}_{2}$-humidified $37^{\circ} \mathrm{C}$ incubator. Rat cultures then were maintained in MEM, $5 \%$ horse serum, and $2 \mathrm{mM}$ L-glutamine in an $8 \% \mathrm{CO}_{2}$-humidified $37^{\circ} \mathrm{C}$ incubator. The growth medium was refreshed twice per week, and the neurons were allowed to mature for $14 \mathrm{~d}$ in culture before being used for experiments. Glia were cultured from $0-3$ d postnatal rats and mice. The procedure was as above for primary neuronal cultures except that the cells were plated on $75 \mathrm{~mm}^{2}$ flasks. After 2 weeks of maturation in vitro, they were plated onto $15 \mathrm{~mm}$ multiwell plates and allowed to reach confluence (3-5 d).

Neurotrophic growth factor treatment. On day in vitro (DIV) 13 the cells were treated with $100 \mathrm{ng} / \mathrm{ml}$ of BDNF, GDNF, NT-3, NT-4, or NGF. Neurotrophic factors were obtained from Intergen (Purchase, NY). Experiments were performed on DIV 14.

Cytotoxicity. The cells were exposed to excitotoxic conditions as described previously (V. Dawson et al., 1991, 1993). Before exposure, the cells were washed with Tris-buffered control salt solution (CSS), $\mathrm{pH} 7.4$, containing (in $\mathrm{mm}$ ): $120 \mathrm{NaCl}, 5.4 \mathrm{KCl}, 1.8 \mathrm{CaCl}_{2}, 25$ Tris- $\mathrm{HCl}$, and 15 glucose. The exposure solutions were administered briefly $(5 \mathrm{~min})$ and then washed off. Then the cells were placed in MEM with $21 \mathrm{~mm}$ glucose and returned to the incubator overnight.

Toxicity was assayed $20-24 \mathrm{hr}$ after exposure to cytotoxic conditions by trypan blue exclusion ( $0.4 \%$ trypan blue in CSS) as described previously (V. Dawson et al., 1991, 1993). Both live cells (cells that exclude trypan blue and are raised dots under Hoffman modulation optics) and dead cells (cells that take up trypan blue and are flat under Hoffman modulation optics) were counted. The percentage of cell death was determined as the ratio of live to dead cells, as compared with the percentage of death in control wells, to account for cell death attributable to mechanical stimulation of the cultures. At least two separate experiments using four separate wells were performed, with a minimum of 4000-12,000 neurons counted per data point. The data were collected and counted by an observer blinded to the treatment protocol.

Data were analyzed with a one-way ANOVA and Fisher's protected least significance difference post hoc test.

NOS catalytic activity. Cortical cultures were washed with CSS and homogenized in $50 \mu \mathrm{l}$ of $50 \mathrm{~mm}$ Tris- $\mathrm{HCl}$ buffer, $\mathrm{pH}$ 7.4, containing $2 \mathrm{~mm}$ EDTA. Homogenates were centrifuged $(1400 \times g)$ for $15 \mathrm{~min}$ at $4^{\circ} \mathrm{C}$. NOS catalytic activity was assayed by monitoring the conversion of $\left[{ }^{3} \mathrm{H}\right]$ arginine to $\left[{ }^{3} \mathrm{H}\right]$ citrulline, as described (Bredt and Snyder, 1990). Tissue supernatant $(25 \mu \mathrm{l})$ was added to $100 \mu \mathrm{l}$ of a solution containing $0.1 \mu \mathrm{Ci}\left[{ }^{3} \mathrm{H}\right]$ arginine and $1 \mathrm{~mm}$ NADPH. $\mathrm{CaCl}_{2}(10 \mu \mathrm{l})$ to a final concentration of $2.25 \mathrm{~mm}$ was added to start the assay, and the samples were incubated for $15 \mathrm{~min}$ at room temperature. The assay was terminated by the addition of $3 \mathrm{ml}$ of HEPES buffer, $\mathrm{pH} 5.5$, containing $2 \mathrm{mM}$ EDTA, and incubates were applied to $0.5 \mathrm{ml}$ of DOWEX AG 50WX-8 (Dow-Corning, Midland, $\mathrm{MI})\left(\mathrm{Na}^{+}\right.$form) columns to separate $\left[{ }^{3} \mathrm{H}\right]$ citrulline (eluate) from $\left[{ }^{3} \mathrm{H}\right]$ arginine. $\left[{ }^{3} \mathrm{H}\right]$ citrulline was quantified by liquid scintillation counting of the eluate. Data were expressed as the percentage of $\left[{ }^{3} \mathrm{H}\right]$ citrulline formation above the basal (no $\mathrm{CaCl}_{2}$ added).

Immunoblotting. Cell cultures were collected in $100 \mu \mathrm{l}$ of Tris- $\mathrm{HCl}$ buffer, $\mathrm{pH}$ 7.4, containing $2 \mathrm{~mm}$ EDTA, $1 \mathrm{~mm} \beta$-mercaptoethanol, $1 \mathrm{~mm}$ PMSF, $1 \mathrm{~mm}$ benzamide, and $10 \mu \mathrm{g} / \mathrm{ml}$ leupeptin. The contents of one well were loaded per lane into a $8 \%$ polyacrylamide gel. After electrophoresis and nitrocellulose membrane transfer, the membranes were incubated overnight with a primary nNOS monoclonal antibody (Transduction Labs, Lexington, KY). The primary antibody was diluted 1:1000 in $3 \%$ bovine serum albumin/0.1\% Tween 20 in phosphate buffer (PB), $\mathrm{pH}$ 7.4. Subsequently, nitrocellulose membranes were incubated for $3 \mathrm{hr}$ with the secondary antibody (1:5000) at room temperature in 5\% nonfat milk in PB, pH 7.4. The labeled bands were visualized by chemiluminescence (Kirkegaard \& Perry, Gaithersburg, MD).

NADPH diaphorase staining. Cells were washed three times with CSS and fixed for $30 \mathrm{~min}$ at $4^{\circ} \mathrm{C}$ in a $4 \%$ paraformaldehyde (PF), $0.1 \mathrm{M} \mathrm{PB}$. The PF solution was washed away with Tris-buffered saline (TBS): $50 \mathrm{~mm}$ Tris- $\mathrm{HCl}$ and $1.5 \% \mathrm{NaCl}, \mathrm{pH}$ 7.4. The reaction solution, containing $1 \mathrm{~mm}$ NADPH, $0.2 \mathrm{~mm}$ nitroblue tetrazolium, $0.2 \%$ Triton X-100 (TX-100), 1.2 mM sodium azide, and $0.1 \mathrm{M}$ Tris- $\mathrm{HCl}, \mathrm{pH} 7.2$, was applied to the fixed cell cultures for $1 \mathrm{hr}$ at $37^{\circ} \mathrm{C}$ (T. Dawson et al., 1991; V. Dawson et al., 1993). The reaction was terminated by washing away the reaction solution with TBS. All diaphorase-positive cells in each well were counted with an inverted microscope.

\section{RESULTS}

\section{Culture-dependent regulation of nNOS expression}

We compared nNOS levels in rat cortical neurons grown on a glial layer versus neurons grown on a Poly-O matrix (Fig. 1). Neurons grown on a glial layer express negligible levels of nNOS neurons, as indicated by NADPH-diaphorase staining (Fig. $1 A$ ). This is in stark contrast to neurons grown on a Poly-O matrix in which 1-2\% of the total neuronal population expresses nNOS, as indicated by NADPH-diaphorase staining (Fig. $1 B$ ). The number of nNOS neurons is enhanced markedly by a $24 \mathrm{hr}$ treatment with BDNF $(100 \mathrm{ng} / \mathrm{ml})$ in cultures grown on a glial layer, whereas there is no significant increase in the number of nNOS neurons in cultures grown on the Poly-O matrix (Fig. 1C,D).

\section{Neurotrophin regulation of nNOS expression in cortical cultures}

Previously we showed that nNOS expression is enhanced by NGF treatment in PC-12 cells (Hirsch et al., 1993). Neurotrophins increase the number of detectable nNOS-expressing neurons, as indicated by NADPH-diaphorase staining in cultures grown on a glial feeder layer (Fig. 2A). BDNF increases the number of nNOS neurons approximately four- to fivefold over control values. GDNF increases the number of nNOS neurons by approximately fourfold, NT-3 and NT-4 increase the number of nNOS neurons by approximately threefold, and NGF fails to influence significantly the number of nNOS neurons in cultures grown on a glial feeder layer (Fig. $2 A$ ). Western blot analysis for nNOS protein and assessments of nNOS catalytic activity by measuring the conversion of $\left[{ }^{3} \mathrm{H}\right]$ arginine to $\left[{ }^{3} \mathrm{H}\right]$ citrulline yield similar results, with BDNF being the most potent inducer of nNOS expression in cortical neurons grown on a glial layer (Fig. $2 B, C)$. Neurotrophins seem to increase both the number of nNOS neurons and the amount of nNOS protein. However, we cannot make definitive statements whether the increase in nNOS protein is from increased nNOS protein per neuron and/or a reflection of more nNOS neurons.

Cortical neurons grown on a Poly-O matrix express a signifi- 

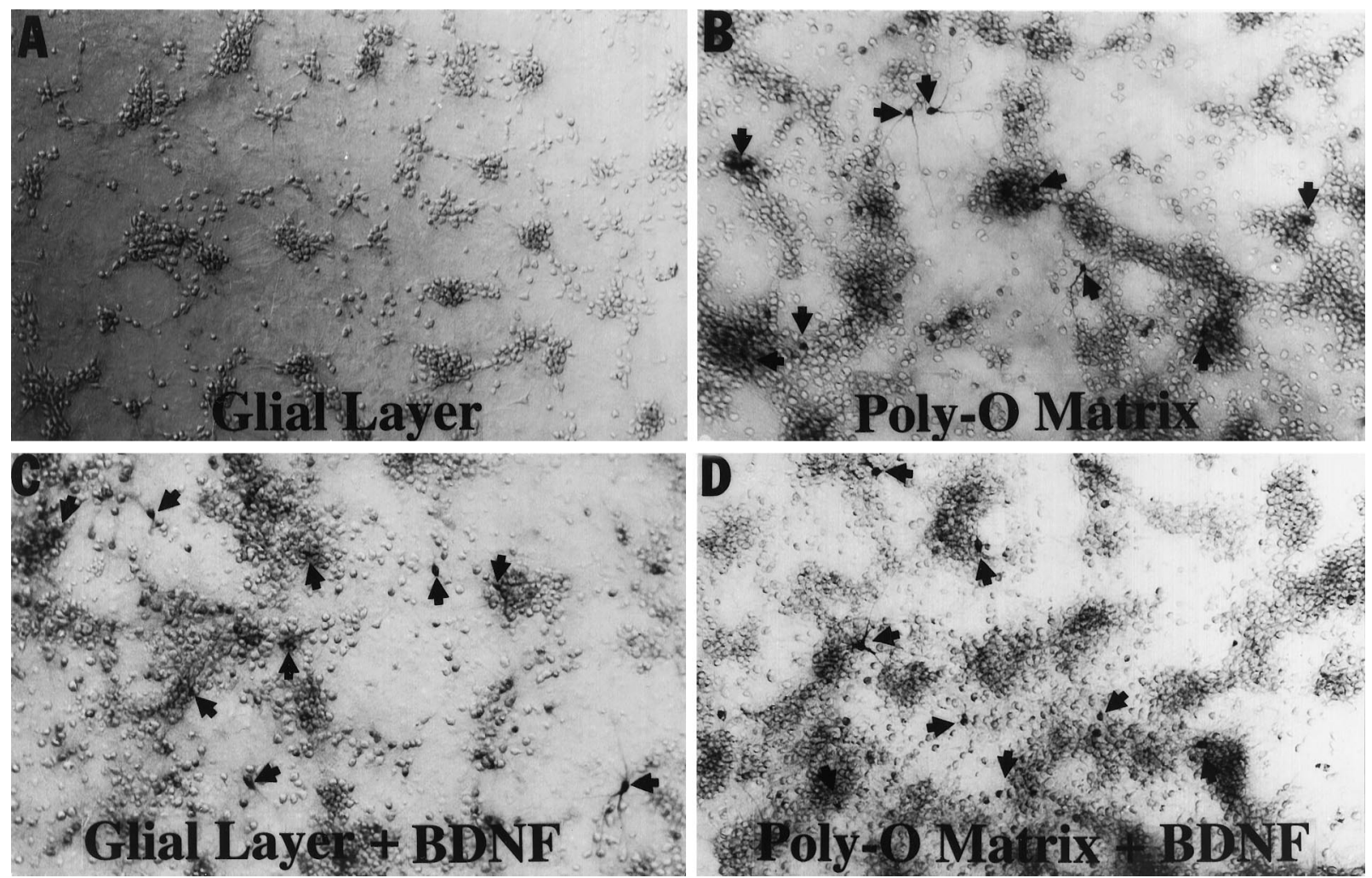

Figure 1. Culture-dependent regulation of nNOS expression. Shown are Hoffman modulation photomicrographs of cortical neurons stained with NADPH-diaphorase depicting neuronal nitric oxide synthase (nNOS) neurons $24 \mathrm{hr}$ after treatment with brain-derived neurotrophic factor $(B D N F$; 100 $\mathrm{ng} / \mathrm{ml}$ ). $A, B$, Control cultures grown either on a glial layer or a polyornithine (Poly-O Matrix) matrix, respectively. $C, D$, Cultures that were treated for $24 \mathrm{hr}$ with $100 \mathrm{ng} / \mathrm{ml}$ BDNF. Neurons cultured on a glial layer express negligible levels of nNOS neurons, the expression of which is increased markedly with BDNF treatment $(A, C)$. Neurons cultured on a Poly-O matrix have a relatively higher expression of nNOS neurons (arrowheads), which is unchanged with BDNF treatment $(B, D)$.

cantly higher quantity of nNOS neurons (Fig. $3 A$ ). nNOS neurons, as indicated by NADPH-diaphorase staining, comprise $\sim 1-2 \%$ of the total neuronal population, consistent with the adult phenotype (Bredt et al., 1991; T. Dawson et al., 1991; Vincent and Kimura, 1992). BDNF treatment does not influence the total number of nNOS neurons (Fig. $3 A$ ) or nNOS catalytic activity (Fig. $3 C$ ), but BDNF increases the amount of nNOS protein, as indicated by Western blot analysis (Fig. $3 B$ ).

\section{Increases in nNOS levels mediate potentiation of NMDA neurotoxicity by neurotrophins}

Rat cortical cultures grown on a glial layer are susceptible to NMDA $(500 \mu \mathrm{M})$ neurotoxicity, with $\sim 20 \%$ cell death above control values (Fig. 4A). This neurotoxicity is not influenced by the competitive nNOS inhibitor nitroarginine-methyl ester (LNAME; $500 \mu \mathrm{M}$ ) or by excess L-arginine (LARG; $5 \mathrm{~mm}$ ). Treatment of cortical cultures grown on glial layers with BDNF $(100 \mathrm{ng} / \mathrm{ml})$ for $24 \mathrm{hr}$ markedly enhances NMDA neurotoxicity, as previously shown (Koh et al., 1995). This marked enhancement of neurotoxicity is NO-dependent, because LNAME completely prevents the enhancement of NMDA neurotoxicity by BDNF and LARG reverses the neuroprotective effects of LNAME (Fig. 4A). An equivalent amount of NMDA-mediated neurotoxicity is observed in cortical cultures grown on a Poly-O matrix, as compared with neurons grown on a glial layer treated with BDNF (Fig. 4B). NMDA neurotoxicity in cortical cultures grown on Poly-O matrix is also NO-dependent, because LNAME blocks the neurotoxicity and the attenuation of neurotoxicity is reversed completely by the substrate LARG (Fig. 4B). Consistent with previous observations, BDNF attenuates the neurotoxic response to NMDA by $\sim 50 \%$. The residual neurotoxicity is dependent partially on NO, because LNAME attenuates this neurotoxicity and LARG reverses the protective effects of LNAME (Fig. 4B).

\section{Culture-independent sensitivity to NO neurotoxicity}

To assess whether neurons grown on a glial layer versus neurons grown on a Poly-O matrix are differentially vulnerable to the toxic effects of NO, we examined neurotoxicity in response to the NO donor sodium nitroprusside (SNP; Fig. 5). Both neuronal culture systems are equally sensitive to the toxic effects of SNP, with 300 $\mu \mathrm{M}$ SNP killing $\sim 50 \%$ of the neurons and $1 \mathrm{~mm}$ SNP killing $\sim 90-100 \%$ of the neurons. BDNF treatment of neurons grown on glial layers does not influence the susceptibility to SNP neurotoxicity, whereas neurons grown on the Poly-O matrix are less susceptible to the toxic effects of $500 \mu \mathrm{M}$ SNP (Fig. 5).

\section{Neurotrophin-mediated enhancement of NMDA neurotoxicity is prevented in $\mathrm{nNOS}^{-}$mice}

Similar to the observations in rat cortical cultures, we observe the same enhancement of NMDA neurotoxicity by BDNF in murine cortical cultures grown on glial layers and a protective effect of BDNF on murine cortical cultures grown on Poly-O matrix (Fig. $6 A, B)$. BDNF enhancement of NMDA neurotoxicity in neurons grown on glial layers is NO-dependent, and NMDA neurotoxicity in cortical cultures grown on Poly-O matrix is also NO-dependent (Fig. 6A,B). To explore and confirm the potential role of induc- 

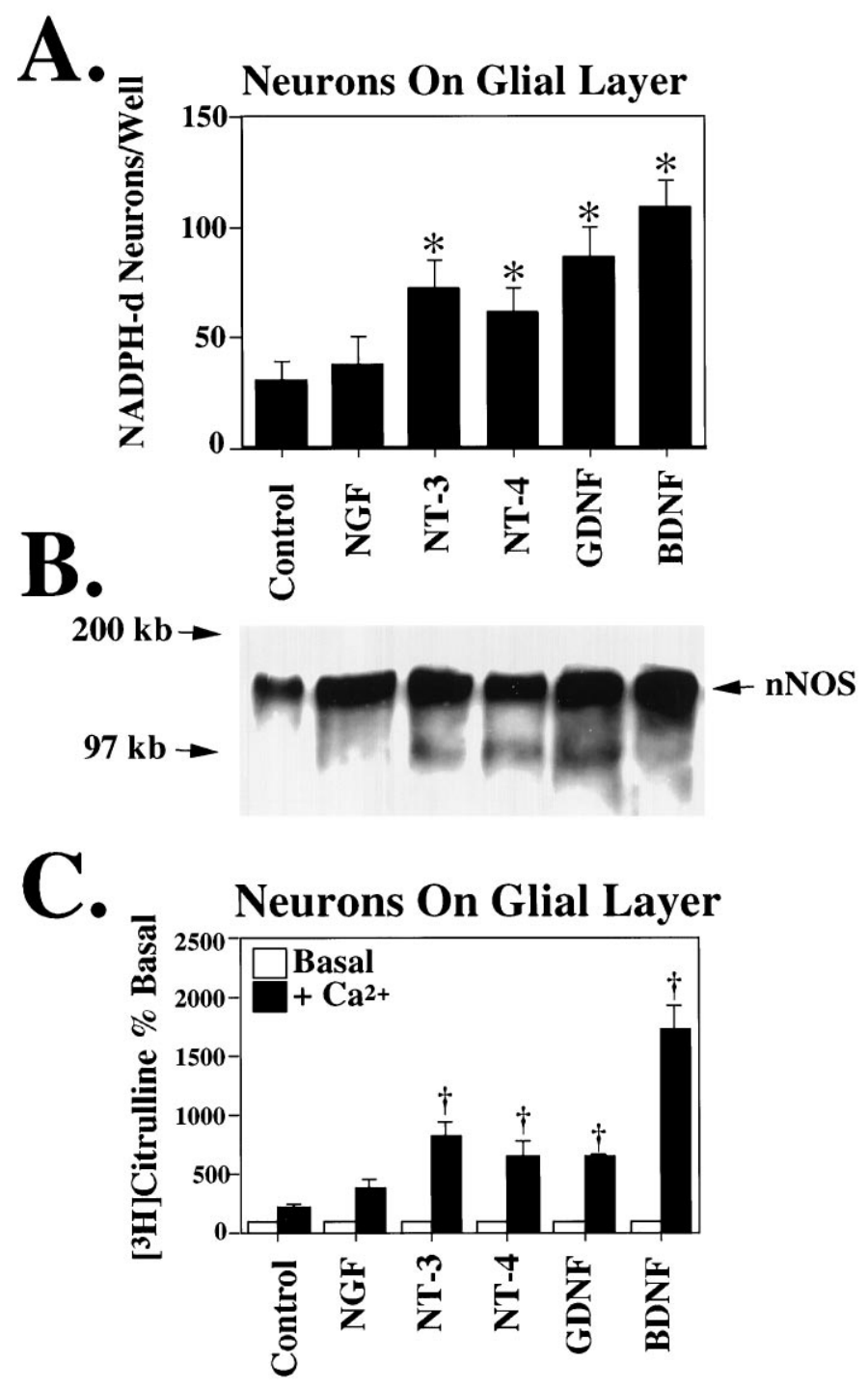

Figure 2. Neurotrophins enhance nNOS expression in cortical neurons grown on a glial layer. $A$, Pretreatment ( $24 \mathrm{hr}$ ) with neurotrophins (100 $\mathrm{ng} / \mathrm{ml}$ ) markedly enhances the number of nNOS neurons, as indicated by $\mathrm{NADPH}$-diaphorase staining of cortical neurons. Each data point represents the mean \pm SEM $(n=8-12)$ of at least two separate experiments. ${ }^{*} p<0.0001$ for $N T-3, N T-4, G D N F$, and $B D N F$, as compared with control cultures. $N G F$ is not significantly different from control. $B$, Neurotrophins increase the amount of $n N O S$ protein, as measured by Western blot analysis. $C$, A parallel increase in NOS catalytic activity is observed. ${ }^{\dagger} p<$ 0.02 for $N T-3, N T-4, G D N F$, and $B D N F$, as compared with control cultures. Each data point represents the mean \pm SEM of at least two separate experiments performed in duplicate.

tion of nNOS by BDNF as the mediator of enhancement of neurotoxicity by neurotrophins, we examined the response of cortical cultures obtained from nNOS ${ }^{-}$mice (Huang et al., 1993) (Fig. 7). As previously shown, $\mathrm{nNOS}^{-}$cortical cultures are markedly resistant to NMDA neurotoxicity (Dawson et al., 1996), and BDNF fails to enhance NMDA neurotoxicity in $\mathrm{nNOS}^{-}$cortical cultures grown on glial layers (Fig. $7 A$ ). BDNF also fails to provide additional protective effects to NMDA neurotoxicity in nNOS $^{-}$cortical cultures grown on a Poly-O matrix (Fig. 7B).

\section{DISCUSSION}

This study provides several lines of evidence indicating that increased nNOS expression mediates, in part, neurotrophin en-
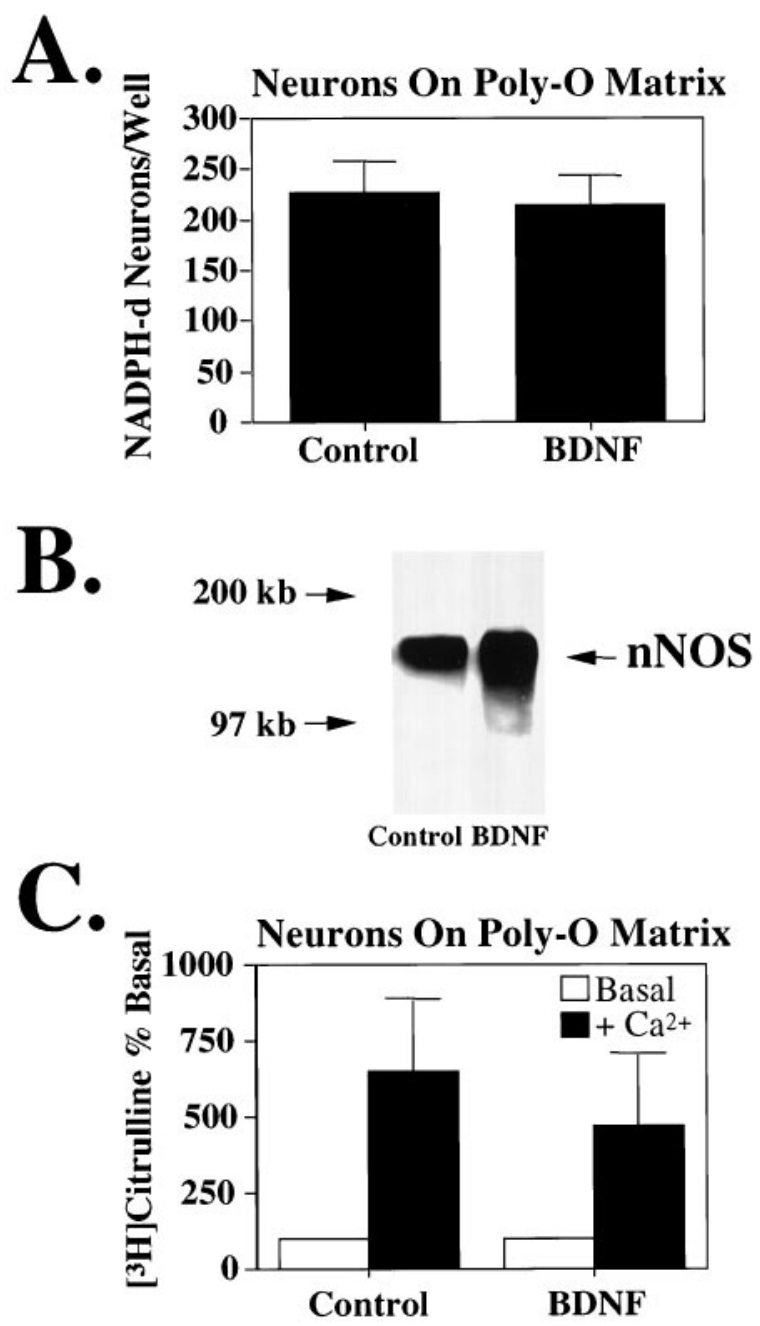

Figure 3. Neurotrophins do not enhance expression of nNOS in cortical neurons grown on a polyornithine (Poly-O) matrix. $A$, Cortical neurons grown on a Poly-O matrix express a significantly higher quantity of nNOS neurons, as indicated by NADPH-diaphorase staining, than cortical neurons grown on a glial layer. Pretreatment $(24 \mathrm{hr})$ with $B D N F$ does not influence the total number of nNOS neurons. Each data point represents the mean \pm SEM $(n=8-12)$ of at least two separate experiments. $B$, BDNF increases the amount of nNOS protein, as measured by Western blot analysis; however, $(C)$ nNOS catalytic activity remains unchanged. Each data point represents the mean \pm SEM of at least two separate experiments performed in duplicate. The number of NADPH-diaphorase neurons and NOS catalytic activity in BDNF-treated cultures is not significantly different from controls.

hancement of NMDA neurotoxicity. Cortical cultures grown on glial layers from both rats and mice express relatively low levels of nNOS and are relatively resistant to the toxic effects of NMDA. BDNF, as well as a variety of other growth factors, markedly enhances the expression of nNOS in cortical cultures grown on glial layers, as evidenced by the greater number of NADPHdiaphorase staining neurons, increased levels of nNOS protein by Western blot analysis, and increased nNOS catalytic activity. Accompanying the increase in nNOS, following BDNF treatment of cortical cultures grown on glial layers, is a NO-dependent component to NMDA neurotoxicity. This neurotoxicity is attenuated by the competitive NOS inhibitor, LNAME, and this neuroprotection is reversed by the NOS substrate, LARG. Moreover, cortical cultures from mice lacking nNOS grown on glial layers are 


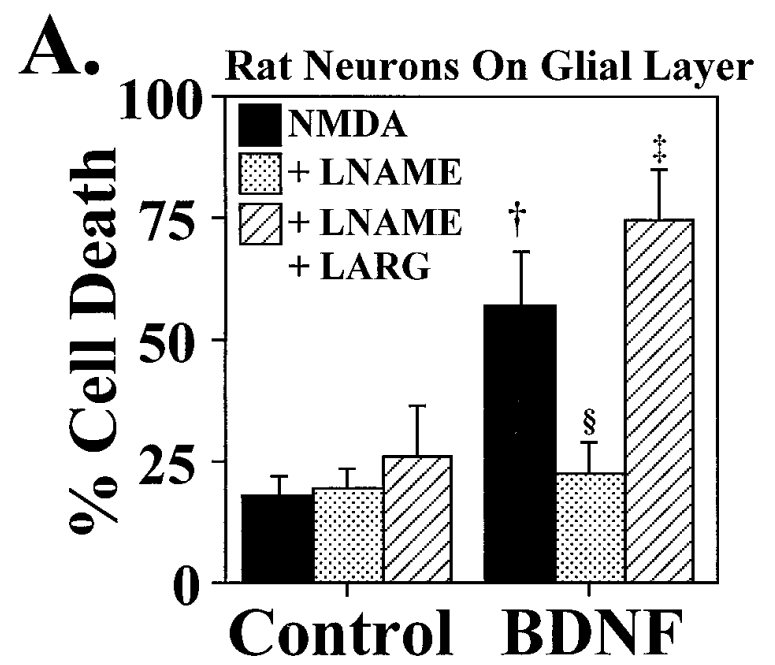

B.

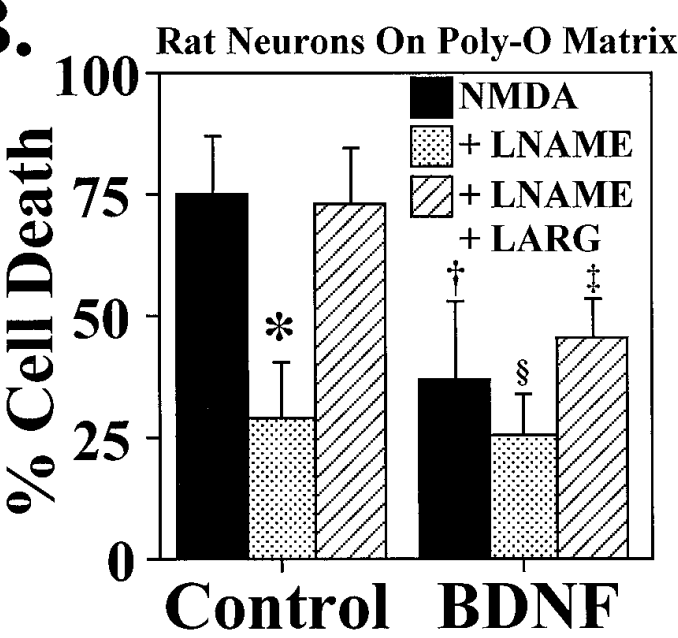

Figure 4. Increases in nNOS levels mediate potentiation of NMDA neurotoxicity by neurotrophins. $A$, Rat cortical neurons grown on a glial layer exhibit NMDA-mediated $(N M D A ; 500 \mu \mathrm{M})$ neurotoxicity, which is not influenced by the competitive nNOS inhibitor nitroarginine-methyl ester $(L N A M E ; 500 \mu \mathrm{M})$ or by excess L-arginine $(L A R G ; 5 \mathrm{mM})$. Pretreatment (24 hr) with $B D N F(100 \mathrm{ng} / \mathrm{ml})$ markedly enhances $N M D A(500 \mu \mathrm{M})$ neurotoxicity $\left({ }^{\dagger} p<0.0001\right)$, which is prevented with $L N A M E(500 \mu \mathrm{M}$; $\left.{ }^{\S} p<0.0001\right)$, and LARG $\left(5 \mathrm{~mm} ;{ }^{\ddagger} p<0.0001\right)$ reverses this neuroprotection. $B$, Cortical neurons grown on a Poly-O matrix demonstrate an equivalent amount of $N M D A$ neurotoxicity to that observed in cortical neurons grown on a glial layer and pretreated with $B D N F(100 \mathrm{ng} / \mathrm{ml})$. This neurotoxicity is also NO-dependent $\left({ }^{*} p<0.0001\right) . B D N F$ treatment of neurons grown on a Poly-O matrix attenuates the neurotoxic response to $N M D A(500 \mu \mathrm{M})$ by $\sim 50 \%\left({ }^{\dagger} p<0.0001\right) . L N A M E\left(500 \mu \mathrm{M} ;{ }^{\circledR} p<0.05\right)$ provides further protection, and $L A R G\left(5 \mathrm{~mm} ;{ }^{\ddagger} p<0.0001\right)$ reverses this protection. Each data point represents the mean \pm SEM $(n=6-12)$ of at least two separate experiments; a minimum of 4000-10,000 neurons was counted.

resistant to the potentiation of NMDA neurotoxicity by BDNF pretreatment. Together, these observations establish nNOS induction as a major mediator of neurotrophin enhancement of NMDA neurotoxicity when cortical neurons are grown on a glial monolayer.

NMDA neurotoxicity is thought to be involved in ischemic stroke damage, because NMDA receptor antagonist decreases infarct volume after middle cerebral artery occlusion (Choi, 1988; Choi and Rothman, 1990; Meldrum and Garthwaite, 1990; Lipton and Rosenberg, 1994). NO may play a major role in NMDA

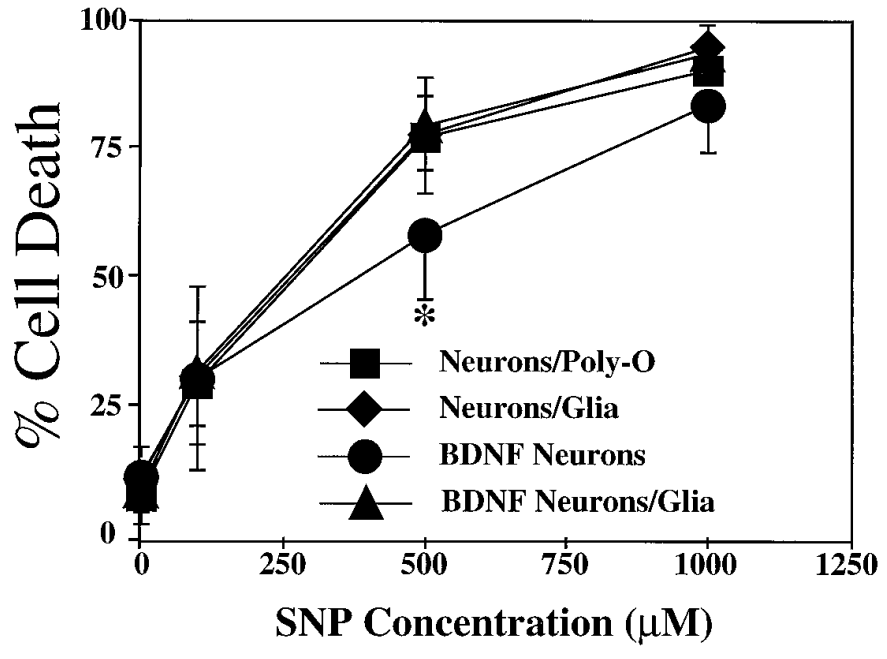

Figure 5. Culture-independent sensitivity to NO neurotoxicity. Cultures were exposed to increasing concentrations of the NO donor sodium nitroprusside (SNP Concentration). Both neuronal culture systems are equally sensitive to the toxic effects of SNP. SNP depleted of NO by preincubating in culture media for $24 \mathrm{hr}$ has no intrinsic toxicity. Pretreatment $(24 \mathrm{hr})$ with $B D N F(100 \mathrm{ng} / \mathrm{ml})$ does not influence SNP toxicity in cortical neurons grown on a glial layer; however, cortical neurons grown on a Poly-O matrix are less susceptible to the toxic effect of $500 \mu \mathrm{M}$ SNP $\left({ }^{*} p<0.001\right)$. Each data point represents the mean \pm SEM $(n=4-6)$ of at least two separate experiments; a minimum of 4000-8000 neurons was counted.

neurotoxicity, because a variety of NOS inhibitors blocks NMDA neurotoxicity in cortical cultures (Dawson and Snyder, 1994; Dawson and Dawson, 1996). Furthermore, neuronal cultures from mice lacking the gene for nNOS are markedly resistant to the toxic effects of NMDA (Dawson et al., 1996). NO-mediated neurotoxicity seems to be specific for NMDA receptor activation, because neurotoxicity elicited by kainate or AMPA receptor activation is resistant to neuroprotection by NOS inhibitors (V. Dawson et al., 1993). A role for NO in NMDA neurotoxicity is supported by several in vivo studies in which stroke damage (Dalkara and Moskowitz, 1994; Iadecola, 1997), mitochondrial toxin-induced striatal injury (Schulz et al., 1995a), and MPTP neurotoxicity are reduced with selective nNOS inhibitors (Schulz et al., 1995b; Przedborski et al., 1996). In addition, there is substantial reduction from injury to these insults in the brains of nNOS $^{-}$mice (Huang et al., 1994; Przedborski et al., 1996; Schulz et al., 1996). Despite the abundance of data implicating NO in NMDA neurotoxicity, there have been some difficulties in replicating these findings. A majority of the difficulties in the in vivo studies probably are related to the initial use of drugs that elicited nonspecific effects. Most NOS inhibitors block all three isoforms and, when administered in vivo, inhibit eNOS, raising blood pressure and reducing cerebral blood flow (Dalkara and Moskowitz, 1994; Iadecola, 1997). The initial discrepancies in the in vivo studies have been clarified by the use of relatively selective nNOS inhibitors (Dalkara and Moskowitz, 1994; Iadecola, 1997) as well as the studies in mice lacking the gene for nNOS (Huang et al., 1994). On the other hand, differences in the potential role of NO in NMDA neurotoxicity in in vitro culture systems has yet to be clarified. Our results indicate that a NO component to NMDA neurotoxicity is critically dependent on the number of nNOS neurons and the level of nNOS protein. The expression of nNOS is critically dependent on the culture condition used, in that 

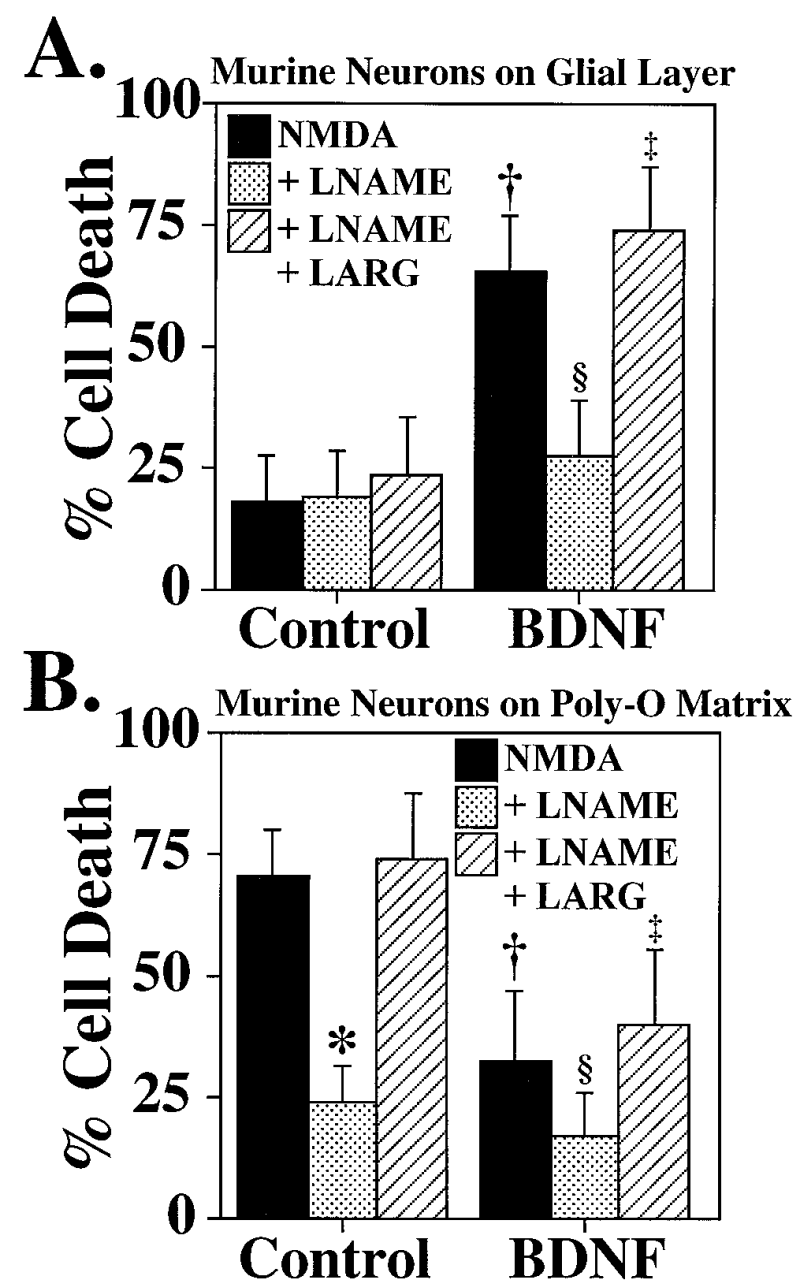

Figure 6. Increases in nNOS levels mediate potentiation of NMDA neurotoxicity by neurotrophins. $A$, Murine cortical neurons grown on a glial layer exhibit NMDA-mediated $(N M D A ; 500 \mu \mathrm{M})$ neurotoxicity, which is not influenced by the competitive nNOS inhibitor nitroarginine-methyl ester $(L N A M E ; 500 \mu \mathrm{M})$ or by excess L-arginine ( $L A R G ; 5 \mathrm{mM})$. Pretreatment $(24 \mathrm{hr})$ with $B D N F(100 \mathrm{ng} / \mathrm{ml})$ markedly enhances $N M D A(500 \mu \mathrm{M})$ neurotoxicity $\left({ }^{\dagger} p<0.0001\right)$, which is prevented with $L N A M E(500 \mu \mathrm{M}$; $\left.{ }^{\S} p<0.0001\right)$, and $L A R G\left(5 \mathrm{~mm} ;{ }^{\ddagger} p<0.0001\right)$ reverses this neuroprotection. $B$, Cortical neurons grown on a Poly-O matrix demonstrate an equivalent amount of $N M D A(500 \mu \mathrm{M})$ NO-dependent neurotoxicity $(* p<0.0001)$ to that observed in cortical neurons grown on a glial layer pretreated with $B D N F(100 \mathrm{ng} / \mathrm{ml})$. BDNF treatment of neurons grown on a Poly-O matrix attenuates the neurotoxic response to $N M D A(500 \mu \mathrm{M})$ by $\sim 50 \%\left({ }^{\dagger} p<0.0001\right), L N A M E\left(500 \mu \mathrm{M} ;{ }^{8} p<0.01\right)$ provides further protection, and $L A R G\left(5 \mathrm{~mm} ;{ }^{\ddagger} p<0.0001\right)$ reverses this protection. Each data point represents the mean $\pm \operatorname{SEM}(n=6-12)$ of at least two separate experiments; a minimum of $4000-10,000$ neurons was counted.

neurons grown on glial layers contain relatively low levels of nNOS, whereas neurons grown on a Poly-O matrix tend to contain high levels of nNOS. nNOS originally was thought to be a constitutively expressed enzyme. However, recent studies indicate that nNOS protein levels can increase after a variety of toxic insults as well as neuronal injury (Solodkin et al., 1992; Roskams et al., 1994; Wu et al., 1994; Zhang et al., 1994; Verge et al., 1995). The upregulation of nNOS by growth factors may play a role in nNOS induction after injury as a number of these factors are induced (Funakoshi et al., 1993; Lindvall et al., 1994; Kokaia et al., 1995). In PC-12 cells the induction of nNOS after NGF administration is thought to be important in the growth arrest of PC-12 cells and

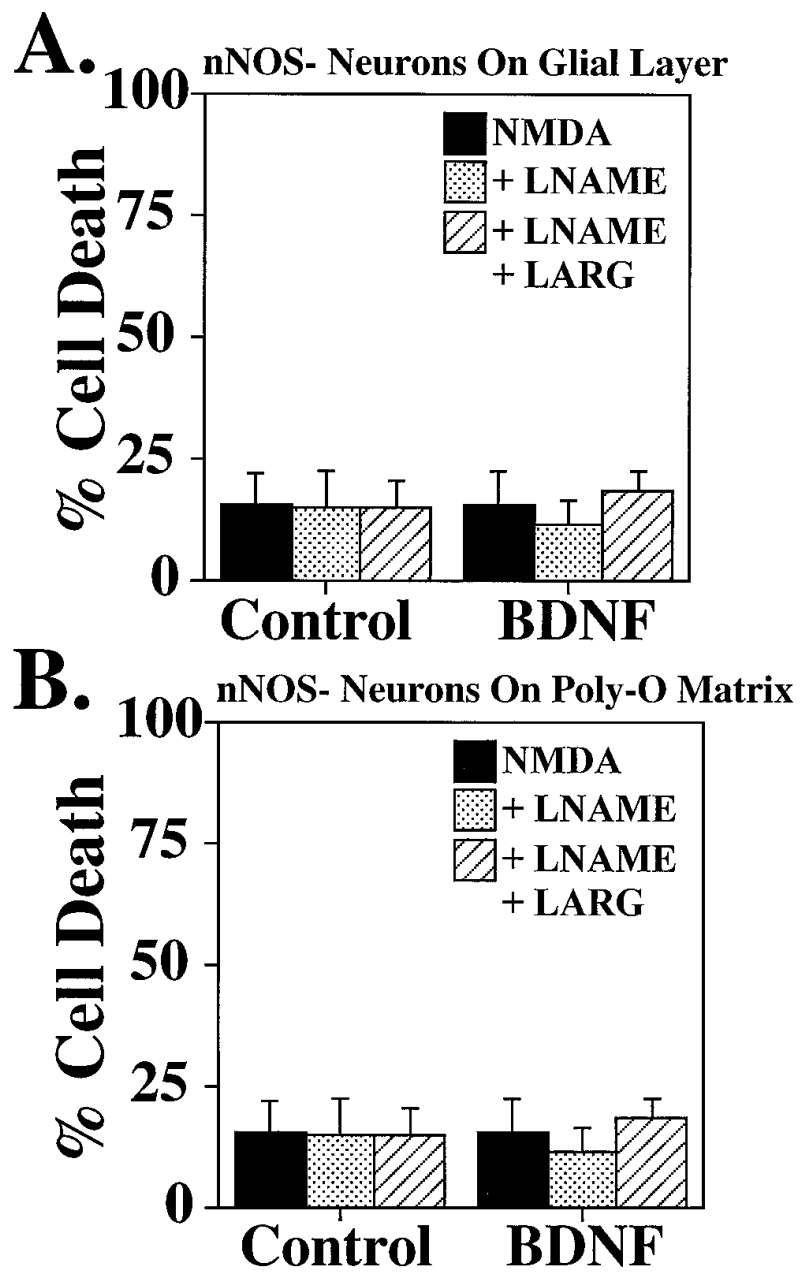

Figure 7. Neurotrophin-mediated enhancement of NMDA neurotoxicity is prevented in $\mathrm{nNOS}^{-}$mice. $A, \mathrm{nNOS}^{-}$cultures are markedly resistant to $N M D A$ neurotoxicity, and $B D N F(100 \mathrm{ng} / \mathrm{ml})$ fails to enhance $N M D A$ neurotoxicity in cortical cultures grown on a glial layer. $B, B D N F$ fails to provide neuroprotection to cortical neurons grown on a Poly-O matrix. Each data point represents the mean $\pm \operatorname{SEM}(n=6-12)$ of at least two separate experiments; a minimum of $4000-10,000$ neurons was counted. None of the determinations is statistically different from another.

may subserve a role in neuronal differentiation (Peunova and Enikolopov, 1995) as well as attainment of a fully differentiated neuronal phenotype (Hirsch et al., 1993). The molecular mechanisms underlying the upregulation of nNOS are not known. Recently, the promoter region for human nNOS has been characterized (Hall et al., 1994). Growth factors induce a variety of transcription factors, including AP-1 and the cyclic AMPresponsive element (Gaiddon et al., 1996), and the nNOS promoter region contains these DNA binding motifs.

Choi and collaborators used neuronal cultures grown on glial layers to demonstrate neurotrophin enhancement of necrotic cell death pathways induced by oxygen glucose deprivation or neurotoxic concentrations of NMDA (Koh et al., 1995). Oxygen glucose deprivation is a useful model of vascular stroke. Neurotoxicity after oxygen glucose deprivation in cultures involves NMDA receptor activation (Choi, 1993) and is mediated primarily by activation of nNOS and overproduction of NO (Dawson et al., 1996). We now confirm these observations and show that the enhancement of NMDA neurotoxicity by neurotrophins is medi- 
ated partially via the increased expression of nNOS. This effect is observed only when neurons are grown on a glial layer. In addition, neurotrophins can affect other cellular systems, such as calcium regulation and upregulate glutamate receptors, which also may contribute to the increased vulnerability of neurons to excitotoxicity (Collazo et al., 1992; Mattson et al., 1993; Cheng et al., 1995). Recent studies suggest that microglia could contribute to the excitotoxic injury to neurons via an indirect mechanism probably secondary to neurocytokine interactions and induction of iNOS (Hewett et al., 1994). Neurons grown on both the glial layer and Poly-O matrix would have microglia because measures were not taken to exclude microglia from the culture paradigms; thus we cannot exclude the possibility that neurotrophin-mediated enhancement of excitotoxicity is attributable to indirect actions of microglia. If microglia are contributing to the enhancement of excitotoxicity, it is unlikely to be via activation of iNOS, because cultures lacking nNOS fail to exhibit neurotrophin-mediated enhancement of excitotoxic injury. When neurons are grown on a Poly-O matrix, BDNF pretreatment is neuroprotective, consistent with numerous previous reports of the protective role of neurotrophins (Mattson et al., 1989, 1995; Fernandez-Sanchez and Novelli, 1993; Nozaki et al., 1993; Prehn et al., 1993; Burke et al., 1994; Cheng and Mattson, 1994; Cheng et al., 1994; Lindholm, 1994; Lindvall et al., 1994; Nakao et al., 1995; Anderson et al., 1996). Thus, the phenotype of neuronal cultures is influenced markedly by the culture paradigm. When neurons are grown on a glial layer, they are being exposed to glia that are $\sim 2-3$ weeks older in age, whereas neurons grown on Poly-O matrix are exposed to glia that are at the same developmental time point. It is likely that neurons and glia signal to each other during development and differentiation and that neurons grown on glial layers do not receive the proper signaling and may remain in a more immature fetal-like state. It is likely that glia of different ages secrete various "factors" that alter the phenotype of the neurons. Consistent with this notion is our observation that conditioned media obtained from glial feeder layers can inhibit completely the nNOS expression of neurons grown on a Poly-O matrix (A. Samdani, V. L. Dawson and T. M. Dawson, unpublished observations). To our knowledge there is no demonstration that neurotrophins enhance the susceptibility to neuronal injury in in vivo studies. Thus, neuronal cultures grown on a Poly-O matrix may represent more accurately the phenotype of the in vivo neuronal population. Moreover, when neurons are grown on a Poly-O matrix, the level of nNOS expression more accurately represents the adult phenotype.

Numerous studies indicate that neurotrophins are neuroprotective after a variety of toxic insults (Burke et al., 1994; Cheng et al., 1994; Lindholm, 1994; Lindvall et al., 1994; Mattson et al., 1995; Nakao et al., 1995; Anderson et al., 1996). We observe similar neuroprotective properties when neurons are grown on a Poly-O matrix. Pretreatment of cortical cultures grown on a Poly-O matrix with BDNF reduces both NMDA neurotoxicity and SNP neurotoxicity. The mechanisms of neurotrophin-mediated neuroprotection are not known. However, recent studies indicate that neurotrophin treatment may stabilize intracellular calcium levels as well as prevent apoptotic death programs (Collazo et al., 1992; Barde, 1994; Barbacid, 1995; Levine et al., 1995; Thoenen, 1995; Tazi et al., 1996). Peptide growth factors may protect against ischemic toxicity in culture by preventing NO toxicity (Maiese et al., 1993). They also prevent peroxynitrite-mediated apoptosis (Estevez et al., 1995). Furthermore, neurotrophins are trophic and may allow neurons to recover from toxic insults (Hefti, 1986; Tuszynski et al., 1990; Yan et al., 1992; Koliatsos et al., 1993; Widmer et al., 1993; Friedman et al., 1995). Alternatively, neurotrophins could induce other neuroprotective proteins and factors that play an as yet undetermined important role.

\section{REFERENCES}

Anderson KD, Panayotatos N, Corcoran TL, Lindsay RM, Wiegand SJ (1996) Ciliary neurotrophic factor protects striatal output neurons in an animal model of Huntington disease. Proc Natl Acad Sci USA 93:7346-7351.

Barbacid M (1995) Neurotrophic factors and their receptors. Curr Opin Cell Biol 7:148-155.

Barde YA (1994) Neurotrophins: a family of proteins supporting the survival of neurons. Prog Clin Biol Res 390:45-56.

Birling MC, Price J (1995) Influence of growth factors on neuronal differentiation. Curr Opin Cell Biol 7:878-884.

Bredt DS, Snyder SH (1990) Isolation of nitric oxide synthetase, a calmodulin-requiring enzyme. Proc Natl Acad Sci USA 87:682-685.

Bredt DS, Snyder SH (1994) Nitric oxide: a physiologic messenger molecule. Annu Rev Biochem 63:175-195.

Bredt DS, Glatt CE, Hwang PM, Fotuhi M, Dawson TM, Snyder SH (1991) Nitric oxide synthase protein and mRNA are discretely localized in neuronal populations of the mammalian CNS together with NADPH diaphorase. Neuron 7:615-624.

Burke MA, Mobley WC, Cho J, Wiegand SJ, Lindsay RM, Mufson EJ, Kordower JH (1994) Loss of developing cholinergic basal forebrain neurons following excitotoxic lesions of the hippocampus: rescue by neurotrophins. Exp Neurol 130:178-195.

Cheng B, Mattson MP (1994) NT-3 and BDNF protect CNS neurons against metabolic/excitotoxic insults. Brain Res 640:56-67.

Cheng B, Goodman Y, Begley JG, Mattson MP (1994) Neurotrophin-4/5 protects hippocampal and cortical neurons against energy deprivationand excitatory amino acid-induced injury. Brain Res 650:331-335.

Cheng B, Furukawa K, O'Keefe JA, Goodman Y, Kihiko M, Fabian T, Mattson MP (1995) Basic fibroblast growth factor selectively increases AMPA-receptor subunit GluR1 protein level and differentially modulates $\mathrm{Ca}^{2+}$ responses to AMPA and NMDA in hippocampal neurons. J Neurochem 65:2525-2536.

Choi DW (1988) Glutamate neurotoxicity and diseases of the nervous system. Neuron 1:623-634.

Choi DW (1993) NMDA receptors and AMPA/kainate receptors mediate parallel injury in cerebral cortical cultures subjected to oxygenglucose deprivation. Prog Brain Res 96:137-143.

Choi DW, Rothman SM (1990) The role of glutamate neurotoxicity in hypoxic-ischemic neuronal death. Annu Rev Neurosci 13:171-182.

Collazo D, Takahashi H, McKay RDG (1992) Cellular targets and trophic functions of neurotrophin-3 in the developing rat hippocampus. Neuron 9:643-656.

Dalkara T, Moskowitz MA (1994) The complex role of nitric oxide in the pathophysiology of focal cerebral ischemia. Brain Pathol 4:49-57.

Davies SW, Beardsall K (1992) Nerve growth factor selectively prevents excitotoxin-induced degeneration of striatal cholinergic neurones. Neurosci Lett 140:161-164.

Dawson TM, Snyder SH (1994) Gases as biological messengers: nitric oxide and carbon monoxide in the brain. J Neurosci 14:5147-5159.

Dawson TM, Bredt DS, Fotuhi M, Hwang PM, Snyder SH (1991) Nitric oxide synthase and neuronal NADPH diaphorase are identical in brain and peripheral tissues. Proc Natl Acad Sci USA 88:7797-7801.

Dawson TM, Steiner JP, Dawson VL, Dinerman JL, Uhl GR, Snyder SH (1993) Immunosuppressant FK506 enhances phosphorylation of nitric oxide synthase and protects against glutamate neurotoxicity. Proc Natl Acad Sci USA 90:9808-9812.

Dawson TM, Hung K, Dawson VL, Steiner JP, Snyder SH (1995) Neuroprotective effects of gangliosides may involve inhibition of nitric oxide synthase. Ann Neurol 37:115-118.

Dawson VL, Dawson TM (1996) Free radicals and neuronal cell death. Cell Death Differ 3:71-78.

Dawson VL, Dawson TM, London ED, Bredt DS, Snyder SH (1991) Nitric oxide mediates glutamate neurotoxicity in primary cortical cultures. Proc Natl Acad Sci USA 88:6368-6371.

Dawson VL, Dawson TM, Bartley DA, Uhl GR, Snyder SH (1993) 
Mechanisms of nitric oxide-mediated neurotoxicity in primary brain cultures. J Neurosci 13:2651-2661.

Dawson VL, Kizushi VK, Huang PL, Snyder SH, Dawson TM (1996) Resistance to neurotoxicity in cortical neuronal cultures from neuronal nitric oxide synthase-deficient mice. J Neurosci 16:2479-2487.

Estevez AG, Radi R, Barbeito L, Shin JT, Thompson JA, Beckman JS (1995) Peroxynitrite-induced cytotoxicity in PC12 cells: evidence for an apoptotic mechanism differentially modulated by neurotrophic factors. J Neurochem 65:1543-1550.

Fernandez-Sanchez MT, Novelli A (1993) Basic fibroblast growth factor protects cerebellar neurons in primary culture from NMDA and nonNMDA receptor-mediated neurotoxicity. FEBS Lett 335:124-131.

Friedman B, Kleinfeld D, Ip NY, Verge VM, Moulton R, Boland P, Zlotchenko E, Lindsay RM, Liu L (1995) BDNF and NT-4/5 exert neurotrophic influences on injured adult spinal motor neurons. J Neurosci 15:1044-1056.

Frim DM, Yee WM, Isacson O (1993) NGF reduces striatal excitotoxic neuronal loss without affecting concurrent neuronal stress. NeuroReport 4:655-658.

Funakoshi H, Frisen J, Barbany G, Timmusk T, Zachrisson O, Verge VM, Persson H (1993) Differential expression of mRNAs for neurotrophins and their receptors after axotomy of the sciatic nerve. J Cell Biol 123:455-465.

Gaiddon C, Loeffler JP, Larmet Y (1996) Brain-derived neurotrophic factor stimulates AP-1 and cyclic AMP-responsive element-dependent transcriptional activity in central nervous system neurons. J Neurochem 66:2279-2286.

Hall AV, Antoniou H, Wang Y, Cheung AH, Arbus AM, Olson SL, Lu WC, Kau CL, Marsden PA (1994) Structural organization of the human neuronal nitric oxide synthase gene (NOS1). J Biol Chem 269:33082-33090.

Hefti F (1986) Nerve growth factor promotes survival of septal cholinergic neurons after fimbrial transections. J Neurosci 6:2155-2162.

Hewett SJ, Csernansky CA, Choi DW (1994) Selective potentiation of NMDA-induced neuronal injury following induction of astrocytic iNOS Neuron 13:487-494.

Hirsch DB, Steiner JP, Dawson TM, Mammen A, Hayek E, Snyder SH (1993) Neurotransmitter release regulated by nitric oxide in PC-12 cells and brain synaptosomes. Curr Biol 3:749-754.

Holtzman DM, Kilbridge J, Bredt DS, Black SM, Li Y, Clary DO, Reichardt LF, Mobley WC (1994) NOS induction by NGF in basal forebrain cholinergic neurons: evidence for regulation of brain NOS by a neurotrophin. Neurobiol Dis 1:51-60.

Holtzman DM, Lee L, Li Y, Chua-Couzens J, Xia H, Bredt DS, Mobley WC (1996) Expression of neuronal NOS in developing basal forebrain cholinergic neurons: regulation by NGF. Neurochem Res 21:867-874.

Huang PL, Dawson TM, Bredt DS, Snyder SH, Fishman MC (1993) Targeted disruption of the neuronal nitric oxide synthase gene. Cell 75:1273-1286.

Huang Z, Huang PL, Panahian N, Dalkara T, Fishman MC, Moskowitz MA (1994) Effects of cerebral ischemia in mice deficient in neuronal nitric oxide synthase. Science 265:1883-1885.

Huber KA, Krieglstein K, Unsicker K (1995) The neurotrophins BDNF, NT-3 and -4, but not NGF, TGF-beta 1 and GDNF, increase the number of NADPH-diaphorase-reactive neurons in rat spinal cord cultures. Neuroscience 69:771-779.

Iadecola C (1997) Bright and dark sides of nitric oxide in ischemic brain injury. Trends Neurosci 20:132-139.

Koh JY, Gwag BJ, Lobner D, Choi DW (1995) Potentiated necrosis of cultured cortical neurons by neurotrophins. Science 268:573-575.

Kokaia Z, Zhao Q, Kokaia M, Elmer E, Metsis M, Smith ML, Siesjo BK, Lindvall O (1995) Regulation of brain-derived neurotrophic factor gene expression after transient middle cerebral artery occlusion with and without brain damage. Exp Neurol 136:73-88.

Koliatsos VE, Clatterbuck RE, Winslow JW, Cayouette MH, Price DL (1993) Evidence that brain-derived neurotrophic factor is a trophic factor for motor neurons in vivo. Neuron 10:359-367.

Levine ES, Dreyfus CF, Black IB, Plummer MR (1995) Differential effects of NGF and BDNF on voltage-gated calcium currents in embryonic basal forebrain neurons. J Neurosci 15:3084-3091.

Lindholm D (1994) Role of neurotrophins in preventing glutamateinduced neuronal cell death. J Neurol 242:S16-S18.

Lindsay RM (1994) Neurotrophic growth factors and neurodegenerative diseases: therapeutic potential of the neurotrophins and ciliary neurotrophic factor. Neurobiol Aging 15:249-251.

Lindvall O, Kokaia Z, Bengzon J, Elmer E, Kokaia M (1994) Neurotrophins and brain insults. Trends Neurosci 17:490-496.

Lipton SA, Rosenberg PA (1994) Excitatory amino acids as a final common pathway for neurologic disorders. N Engl J Med 330:615-622.

Maiese K, Boniece I, DeMeo D, Wagner JA (1993) Peptide growth factors protect against ischemia in culture by preventing nitric oxide toxicity. J Neurosci 13:3034-3040.

Marletta MA (1994) Nitric oxide synthase: aspects concerning structure and catalysis. Cell 78:927-930.

Mattson MP, Murrain M, Guthrie PB, Kater SB (1989) Fibroblast growth factor and glutamate: opposing roles in the generation and degeneration of hippocampal neuroarchitecture. J Neurosci 9:3728-3740.

Mattson MP, Kumar KN, Wang H, Cheng B, Michaelis EK (1993) Basic FGF regulates the expression of a functional $71 \mathrm{kDa}$ NMDA receptor protein that mediates calcium influx and neurotoxicity in hippocampal neurons. J Neurosci 13:4575-4588.

Mattson MP, Lovell MA, Furukawa K, Markesbery WR (1995) Neurotrophic factors attenuate glutamate-induced accumulation of peroxides, elevation of intracellular $\mathrm{Ca}^{2+}$ concentration, and neurotoxicity and increase antioxidant enzyme activities in hippocampal neurons. J Neurochem 65:1740-1751.

Meldrum B, Garthwaite J (1990) Excitatory amino acid neurotoxicity and neurodegenerative disease. Trends Pharmacol 11:379-387.

Nakao N, Kokaia Z, Odin P, Lindvall O (1995) Protective effects of BDNF and NT-3 but not PDGF against hypoglycemic injury to cultured striatal neurons. Exp Neurol 131:1-10.

Nathan CF (1992) Nitric oxide as a secretory product of mammalian cells. FASEB J 6:3051-3064.

Nathan CF, Xie QW (1994) Nitric oxide synthases: roles, tolls, and controls. Cell 78:915-918.

Nozaki K, Finklestein SP, Beal MF (1993) Basic fibroblast growth factor protects against hypoxia-ischemia and NMDA neurotoxicity in neonatal rats. J Cereb Blood Flow Metab 13:221-228.

Peunova N, Enikolopov G (1995) Nitric oxide triggers a switch to growth arrest during differentiation of neuronal cells. Nature 375:68-73.

Prehn JH, Backhauss C, Krieglstein J (1993) Transforming growth factor-beta 1 prevents glutamate neurotoxicity in rat neocortical cultures and protects mouse neocortex from ischemic injury in vivo. J Cereb Blood Flow Metab 13:521-525.

Przedborski S, Jackson-Lewis V, Yokohama R, Shibata T, Dawson VL, Dawson TM (1996) Role of neuronal nitric oxide in 1-methyl-4phenyl-1,2,3,6-tetrahydropyridine (MPTP)-induced dopaminergic neurotoxicity. Proc Natl Acad Sci USA 93:4565-4571.

Roskams AJ, Bredt DS, Dawson TM, Ronnett GV (1994) Nitric oxide mediates the formation of synaptic connections in developing and regenerating olfactory receptor neurons. Neuron 13:289-299.

Schmidt HHHW, Walter U (1994) NO at work. Cell 78:919-925.

Schulz JB, Matthews RT, Jenkins BG, Ferrante RJ, Siwek D, Henshaw DR, Cipolloni PB, Mecocci P, Kowall NW, Rosen BR, Beal MF (1995a) Blockade of neuronal nitric oxide synthase protects against excitotoxicity in vivo. J Neurosci 15:8419-8429.

Schulz JB, Matthews RT, Muqit MMK, Browne SE, Beal MF (1995b) Inhibition of neuronal nitric oxide synthase by 7-nitroindazole protects against MPTP-induced neurotoxicity in mice. J Neurochem 64:936-939.

Schulz JB, Huang PL, Matthews RT, Passov D, Fishman MC, Beal MF (1996) Striatal malonate lesions are attenuated in neuronal nitric oxide synthase knock-out mice. J Neurochem 67:430-433.

Shigeno T, Mima T, Takakura K, Graham DI, Kato G, Hashimoto Y, Furukawa S (1991) Amelioration of delayed neuronal death in the hippocampus by nerve growth factor. J Neurosci 11:2914-2919.

Solodkin A, Traub RJ, Gebhart GF (1992) Unilateral handpaw inflammation produces a bilateral increase in NADPH-diaphorase histochemical staining in the rat lumbar spinal cord. Neuroscience 51:495-499.

Tazi A, Le BS, Lamghitnia HO, Vincent JD, Czernichow P, Scharfmann $\mathrm{R}$ (1996) Neurotrophin-3 increases intracellular calcium in a rat insulin-secreting cell line through its action on a functional TrkC receptor. J Biol Chem 271:10154-10160.

Thoenen H (1995) Neurotrophins and neuronal plasticity. Science 270:593-598.

Tuszynski MH, U HS, Amaral DG, Gage FH (1990) Nerve growth factor 
infusion in the primate brain reduces lesion-induced cholinergic neuronal degeneration. J Neurosci 10:3604-3614.

Verge VMK, Richardson PM, Wisenfeld-Hallin Z, Hokfelt T (1995) Differential influence of nerve growth factor on neuropeptide expression in vivo: a novel role in peptide suppression in adult sensory neurons. J Neurosci 15:2081-2096.

Vincent SR, Kimura H (1992) Histochemical mapping of nitric oxide synthase in the rat brain. Neuroscience 46:755-784.

Widmer HR, Knusel B, Hefti F (1993) BDNF protection of basal forebrain cholinergic neurons after axotomy: complete protection of p75NGFR-positive cells. NeuroReport 4:363-366.

Wu W, Liuzzi FJ, Schinco FP, Depto A, Li Y, Mong JA, Dawson TM,
Snyder SH (1994) Induction of neuronal nitric oxide synthase in spinal neurons by traumatic injury. Neuroscience 61:719-726.

Yan Q, Elliott J, Snider WD (1992) Brain-derived neurotrophic factor rescues spinal motor neurons from axotomy-induced cell death. Nature 360:753-755.

Yun H-Y, Dawson VL, Dawson TM (1996) Neurobiology of nitric oxide. Crit Rev Neurobiol 10:291-316.

Zhang ZG, Chopp M, Gautam S, Zaloga C, Zhang RL, Schmidt HHHW, Pollock JS, Forstermann U (1994) Upregulation of neuronal nitric oxide synthase and mRNA, and selective sparing of nitric oxide synthase-containing neurons after focal cerebral ischemia in rat. Brain Res 654:85-95. 